\title{
Multivisceral resections for locally advanced colorectal cancer after preoperative treatment
}

\author{
TAKESHI NISHIKAWA, SOICHIRO ISHIHARA, SHIGENOBU EMOTO, MANABU KANEKO, \\ KOJI MURONO, KAZUHITO SASAKI, KENSUKE OTANI, TOSHIAKI TANAKA, TOMOMICHI KIYOMATSU, \\ KEISUKE HATA, KAZUSHIGE KAWAI, HIROAKI NOZAWA and TOSHIAKI WATANABE
}

Department of Surgical Oncology, The University of Tokyo, Tokyo 113-8655, Japan

Received July 28, 2017; Accepted January 17, 2018

DOI: $10.3892 / \mathrm{mco} .2018 .1559$

\begin{abstract}
Multivisceral resection for colorectal cancer invading into the adjacent organs may often be difficult and may involve serious complications. Preoperative therapy may facilitate resection with safe margins. Between August 2007 and July 2016, 23 patients with colorectal cancer invading into the adjacent organs treated with preoperative treatment (chemoradiotherpay, chemotherapy, radiotherapy) were retrospectively investigated. All 23 patients received surgery with curative intent. Four patients had distant metastases at the time of diagnosis. Two patients had distant metastasis after preoperative treatment. The mean operative time was $535.3 \pm 185.5 \mathrm{~min}$ and the median amount of blood loss was $1,050 \mathrm{ml}$. Histopathological examination revealed malignant infiltration of the adjacent organs in 14 patients $(60.9 \%)$. R0 resection rate was $73.9 \%$. Postoperative complications were identified in nine patients $(39.1 \%)$ and a high incidence of infectious complications was observed. Patients with curative resection showed a significantly better survival than patients with $\mathrm{R} 1$ or $\mathrm{R} 2$ resection $(\mathrm{P}<0.01)$. Multivisceral resection for locally advanced colorectal cancer invading into the adjacent organ after preoperative treatment may be performed with acceptable morbidity and minimal mortality. R0 resection improves the prognosis of patients with locally advanced colorectal cancer invading into the adjacent organ after preoperative treatment.
\end{abstract}

Correspondence to: Dr Takeshi Nishikawa, Department of Surgical Oncology, The University of Tokyo, 7-3-1 Hongo, Bunkyo-ku, Tokyo 113-8655, Japan

E-mail: takn-tky@umin.ac.jp

Abbreviations: CRT, chemoradiotherapy; CTx, chemotherapy; RT, radiotherapy; $\mathrm{CT}$, computed tomography; $\mathrm{MRI}$, magnetic resonance imaging; CR, complete response

Key words: colorectal cancer, invasion, chemoradiotherapy, chemotherapy, radiotherapy

\section{Introduction}

Colorectal cancer is one of the most common malignancies worldwide, and in recent years, the incidence rates in Japanese males have exceeded the peak of incidence observed in the US, Canada and New Zealand (1). Of all cancer deaths in Japan, the age-adjusted mortality rate of colorectal cancer is ranked third in men and second in women (1). Colorectal cancer invading into the adjacent organs/structures is detected in 5 to $20 \%$ of all surgical interventions performed for the management of colorectal cancer (2). In those cases, surgeons are faced intraoperatively with the problem of having to decide whether adhesions between the tumor and the surrounding organs/structures are due to malignant infiltration or to benign peritumoral inflammation. However, the intraoperative assessments of the etiology of such adhesions are often inaccurate. So, generally, the standard operative management of primary colorectal cancer adherent to adjacent organs is en bloc multivisceral resection to obtain clear resection margin (R0). But under these locally advanced conditions, extended en bloc multivisceral resection might be often difficult and might involve serious complications, leading to an increase in morbidity and mortality. Given preoperatively treatment [chemoradiotherpay (CRT), chemotherapy (CTx), radiotherapy $(\mathrm{RT})]$ may reduce tumor size and facilitate resection with safe distal and radial margins.

The aim of this study is to clarify the short- and long-term outcomes of preoperative treatment (CRT, CTx, RT) for locally advanced colorectal cancer invading into the adjacent organ(s).

\section{Patients and methods}

Between August 2007 and July 2016, a total of 23 patients with histologically confirmed primary adenocarcinoma of the colon/ rectum with clinical suspicious of invasion into the adjacent organ (clinical T4b), who were treated with preoperative treatment (CRT, CTx or RT), were studied retrospectively at the University of Tokyo Hospital. All the patients, except for those with obstruction, received a total colonoscopy. And all patients preoperatively studied with thoracic and abdominal computed tomography (CT) and positron emission tomography (PET) if needed. Clinical T category was determined by CT for patients with colon cancer, and pelvic magnetic resonance 
imaging (MRI) for patients with rectal cancer. Patients with recurrent colorectal cancer and patients who received palliative surgery from the beginning were excluded from this study. The study was conducted with the approval of the Ethics Committee of the University of Tokyo [no. 3252-(5)]

Patients, who had cancer in the middle or lower part of the rectum with tumor invading further than the muscularis propia (T3 or T4) without distant metastases, received preoperative CRT. A total of 18 patients received a total dose of 50.4 Gy in 28 fractions (1.8 Gy/day). Preoperative chemotherapy was started at the same time as radiotherapy. Patients received the 5-fluorouracil-based chemotherapy in the following regimens: 14 tegafur-uracil and leucovorin, one S-1. Three patients did not receive concurrent chemotherapy during radiation because of liver dysfunction in two cases and elder age in the other. Surgery, including total mesorectal excision or tumor-specific mesorectal excision techniques, was performed 6 to 8 weeks after the completion of CRT. Lateral pelvic lymph node dissection was selectively performed in cases with suspicion of lateral pelvic lymph node metastasis in the preoperative MRI before CRT regardless of its response to CRT. In this study, lymph nodes with diameter of $8 \mathrm{~mm}$ or larger in the MRI were considered as suspicious of metastasis. Rest five patients received preoperative chemotherapy because of colon cancer or distant metastasis at the time of diagnosis. Surgery was performed when curative resection was possible. During the initial stage of the study, the operations were performed via a laparotomy. In our institute, until 2011, the laparoscopic surgery was limited to patients with colon cancer preoperatively diagnosed as early stage, but the application of the laparoscopic surgery gradually increased after 2012, and presently, laparoscopic surgery is indicated in almost all feasible patients. Furthermore, from 2012 the robotic surgery was introduced for patients with rectal cancer who opt for this procedure. Robotic surgery was considered as a laparoscopic technique and was included in the laparoscopic surgery. Conversion of laparoscopic surgery to open surgery was defined as an abdominal incision different from that planned at the start of the operation.

The results of clinical and pathological examination were classified according to the TNM classification of The International Union Against Cancer (UICC) (3). In addition, response to preoperative treatment was determined by the histologic examination of the primary tumor according to a semi-quantitative classification of the Japanese Society for Cancer of the Colon and rectum (4) as follows: i) Grade $1 \mathrm{a}$, less than one third of cancer had degraded, necrotized, or dissapered; ii) Grade 1b, from one thierd to two thirds of cancer had degraded; iii) Grade 2, more than two thirds of cancer had degraded; and iv) Grade 3, complete response (CR). Short-term morbidity and mortality was defined as 30-day or in-hospital morbidity and mortality according to the ClavienDindo classification.

Statistical analysis. For categorical variables, data were presented as frequencies and percentage. Continuous variables were shown as median or mean \pm standard deviation (SD) and were estimated using Mann-Whitney $U$ test or a t test. Survival was calculated in months from the time of surgery to the last follow-up or recurrence/death. Survival analyses were made using the Kaplan-Meier survival curves. Differences in
Table I. Patient characteristics.

Characteristic

Patients $(n=23)$

Sex

Male

10

Female

Age (years)

$60(46-88)$

Preoperative therapy

Chemoradiotherapy $\quad 15$

Radiotherapy 3

Chemotherapy 5

Colostomy before preoperative therapy

Yes

5

No

18

Distant metastasis before preoperative therapy

4

Distant metastasis after preoperative

survival between groups were assessed using the log-rank test. Associations were considered significant when $\mathrm{P}<0.05$.

\section{Results}

Of 23 patients, the median age was 60 years, and there were 10 men and 13 women. All 23 patients had no severe complication associated with preoperative treatment. Characteristics of patients are shown in Table I. Four patients with clinical suspicious of invasion into the adjacent organ had distant metastases at the time of diagnosis (lung metastasis in two, liver metastasis in one and liver and peritoneal metastases in one). Two patients had distant metastasis after preoperative CRT: inguinal lymph node metastasis in one and liver and lung metastases in one. Median follow up period was 19.9 months (6.2-111.0 years).

Operative data are shown in Table II. All 23 patients received surgery with curative intent. 16 patients received open surgery and seven patients, laparoscopic/robotic surgery. Conversion to open surgery was not required in any of the cases in this study. Two patients received bilateral lateral lymph node dissection, because bilateral swollen lateral lymph nodes were detected by the preoperative MRI taken prior to the CRT. Mean operative time was $535.3 \pm 185.5 \mathrm{~min}$ (162-1,044 $\mathrm{min})$ and the median amount of blood loss was $1,050 \mathrm{ml}(90-25,320 \mathrm{ml})$. No intraoperative complications occurred during the study period. Seven of nine recent cases received laparoscopic/robotic surgery, and the operative times were similar between the laparoscopic/robotic surgery group and the open surgery group (471.9 \pm 94.5 vs. $563.0 \pm 210.2 \mathrm{~min}$, $\mathrm{P}=0.2885$, respectively). The amount of blood loss was significantly smaller in patients treated with laparoscopic/robotic surgery than in those receiving open surgery (430 vs. 1,485 ml, $\mathrm{P}<0.01$, respectively).

Pathological characteristics are shown in Table III. Histopathologic examination showed malignant infiltration of the adherent organs in 14 patients $(60.9 \%)$. The most common procedures were partial vaginal resection performed in 10 patients. Details of the adjacent organ resections are 
Table II. Operative data.

\begin{tabular}{|c|c|c|}
\hline Characteristic & Patients & P-value \\
\hline \multicolumn{3}{|l|}{ Approach } \\
\hline Open surgery & 16 & \\
\hline Laparoscopic/robotic surgery & 7 & \\
\hline \multicolumn{3}{|l|}{ Procedure } \\
\hline Colectomy & 3 & \\
\hline Low anterior resection & 7 & \\
\hline Intersphincteric & 1 & \\
\hline Miles' operation & 8 & \\
\hline Total pelvic & 2 & \\
\hline Hartmann's operation & 2 & \\
\hline \multicolumn{3}{|l|}{ Resection of the adjacent $\operatorname{organ}(\mathrm{s})$} \\
\hline Yes & $20(86.9 \%)$ & \\
\hline No & 2 & \\
\hline \multicolumn{3}{|l|}{ Operative time (min) } \\
\hline Mean \pm SD (range) & $\begin{array}{c}535.3 \pm 185.5 \\
(162-1,044)\end{array}$ & \\
\hline Laparoscopic/robotic surgery & & 0.2885 \\
\hline Mean \pm SD (range) & $\begin{array}{c}471.9 \pm 94.5 \\
(339-593)\end{array}$ & \\
\hline \multicolumn{3}{|l|}{ Open surgery } \\
\hline Mean \pm SD (range) & $\begin{array}{c}563.0 \pm 210.2 \\
(162-1,044)\end{array}$ & \\
\hline \multicolumn{3}{|l|}{ Blood loss (ml) } \\
\hline Median (range) & $\begin{array}{c}1,050 \\
(90-25,320)\end{array}$ & \\
\hline Laparoscopic/robotic surgery & & $<0.01$ \\
\hline Median (range) & $\begin{array}{c}430 \\
(100-1.110)\end{array}$ & \\
\hline \multicolumn{3}{|l|}{ Open surgery } \\
\hline Median (range) & $\begin{array}{c}1,485 \\
(90-25,320)\end{array}$ & \\
\hline
\end{tabular}

SD, standard deviation.

(

shown in Table III. No pathological complete response (pCR) was observed. Curative surgery was performed in 18 patients $(78.3 \%)$. Two patient had a $\mathrm{R} 1$ resection because histopathologic examination revealed malignant infiltration of the resected margin in the vagina in one and in the live in one. Two patients with lung metastasis at the time of diagnosis received concomitant Miles' operation but resulted in palliative resection because new lung metastases were diagnosed prior to the next lung surgery. And one patient with liver and lung metastases received concomitant Miles' operation and liver resection, but resulted in palliative resection because the inguinal lymph node metastasis and a new lung metastasis were diagnosed prior to the next lung surgery. The median tumor size was $40 \mathrm{~mm}$ and eight patients had lymph node metastasis, and the number of harvested lymph nodes was $19.3 \pm 14.1$ and was similar between the laparoscopic/robotic surgery group
Table III. Pathological characteristics.

\begin{tabular}{|c|c|c|}
\hline Characteristic & Patients $(n=23)$ & P-value \\
\hline \multicolumn{3}{|l|}{$\mathrm{pT} 4 \mathrm{~b} / \mathrm{cT} 4 \mathrm{~b}$} \\
\hline Overall & $14 / 23(60.9 \%)$ & \\
\hline Prostate & $1 / 5(20.0 \%)$ & \\
\hline Seminal vesicle & $1 / 5(20.0 \%)$ & \\
\hline Bladder & $2 / 3(66.7 \%)$ & \\
\hline Uterus & $1 / 2(50.0 \%)$ & \\
\hline Vagina & $7 / 10(70.0 \%)$ & \\
\hline $\begin{array}{l}\text { Gastrointestinal tract } \\
\text { (stomach, small intestine, rectum) }\end{array}$ & $3 / 3(100 \%)$ & \\
\hline \multicolumn{3}{|l|}{ Pathologic regression grade } \\
\hline Grade1a & 14 & \\
\hline Grade1b & 4 & \\
\hline Grade2 & $5(21.7 \%)$ & \\
\hline Grade3 & 0 & \\
\hline \multicolumn{3}{|l|}{ Residual tumor classification } \\
\hline R0 & $18(78.3 \%)$ & \\
\hline $\mathrm{R} 1$ & 2 & \\
\hline $\mathrm{R} 2$ & 3 & \\
\hline \multicolumn{3}{|l|}{ Tumor location } \\
\hline Colon & 4 & \\
\hline Rectum & 19 & \\
\hline \multicolumn{3}{|l|}{ Histology } \\
\hline Well differentiated & 11 & \\
\hline Moderately differentiated & 10 & \\
\hline Other & 2 & \\
\hline \multicolumn{3}{|l|}{ Tumor size (mm) } \\
\hline Median (range) & $40(10-150)$ & \\
\hline \multicolumn{3}{|l|}{ Lymph node metastasis } \\
\hline Absent & 15 & \\
\hline Present & 8 & \\
\hline \multicolumn{3}{|l|}{ Number of harvested lymph nodes } \\
\hline Mean \pm SD (range) & $\begin{array}{l}19.3 \pm 14.1 \\
(2-55)\end{array}$ & \\
\hline Laparoscopic/robotic surgery & & 0.9719 \\
\hline Mean \pm SD (range) & $\begin{array}{l}19.1 \pm 17.4 \\
(4-55)\end{array}$ & \\
\hline \multicolumn{3}{|l|}{ Open surgery } \\
\hline Mean \pm SD (range) & $\begin{array}{l}19.4 \pm 13.0 \\
(2-44)\end{array}$ & \\
\hline
\end{tabular}

SD, standard deviation.

and the open surgery group $(19.1 \pm 17.4$ vs. $19.4 \pm 13.0 \mathrm{~min}$, $\mathrm{P}=0.9719$, respectively).

Postoperative events are shown in Table IV. Postoperative complications were found in nine patients (39.1\%) and showed high incidence of infectious complications such as wound infection, intraabdominal abscess and urinary tract infection. Postoperative ileus was observed in two cases. One patient 
Table IV. Morbidity and mortality.

\begin{tabular}{lc}
\hline Characteristic & Patients $(\mathrm{n}=23)$ \\
\hline Morbidity & \\
Overall & $9(39.1 \%)$ \\
Wound infection & 1 \\
Intraabdominal abscess & 4 \\
Urinary infection & 2 \\
Urinary retention & 1 \\
Ileus & 2 \\
Mortality & $1(4.3 \%)$ \\
\hline
\end{tabular}

(4.3\%) received open surgery died in the postoperative period due to intraabdominal abscess.

Disease-free survival according to $\mathrm{R}$ classification is shown in Fig. 1A. Patients with curative surgery showed a significantly better disease-free survival than the patient with R1 surgery $(\mathrm{P}<0.05)$. One-, 3- and 5-year disease-free survival rates of patients who received curative resection were $77.4,63.8$ and $63.8 \%$, respectively. Six of 17 patients with curative surgery had recurrence. One patient had local recurrence, one local and liver metastases, and four distant metastasis (two dissemination and two lymph node). On the other hand, all two patients with R1 surgery had recurrence within two years. One patient with R1 surgery had lymph node metastasis and the other patient who received postoperative chemotherapy had skin and brain metastasis 1 year after the surgery. Overall survival according to R classification is shown in Fig. 1B. One-, 3- and 5-year cancer-specific survival rates of patients who received curative resection were $100,85.7$ and $75.0 \%$, respectively. None of the patients who received $\mathrm{R} 1$ and $\mathrm{R} 2$ resection survived more than 2 years. Patients with curative surgery showed a significantly better survival than the patient with R1 surgery or those with $\mathrm{R} 2$ surgery $(\mathrm{P}<0.01)$.

\section{Discussion}

It is difficult to differentiate malignant infiltration from inflammatory adhesions during surgery. The surgeon may interpret inflammatory adhesions as macroscopic invasion, but only the histopathological analysis can provide the precise differentiation. Historically, the standard operative management of primary colorectal cancer with a potentially malignant adhesion to the adjacent organs is en bloc multivisceral resection to obtain clear resection margin (R0). In our study, malignant invasion was histologically confirmed in $60.9 \%$ of patients presenting with the primary tumor adherent to the adjacent organs. This finding is similar to previous reports $(5,6)$. On the other hand, some previous studies demonstrated that adhesions between tumor and other organs harbor malignant cells in $25-40 \%$ of cases, which are lower rates compared with our study $(2,7,8)$. It is reported that the local recurrence rate was higher when adherent organs were dissected from the tumor than in cases in whom en bloc resection was performed (69 vs. $18 \%$, respectively) (9). And it is also reported that the five-year survival rate was $17 \%$ after
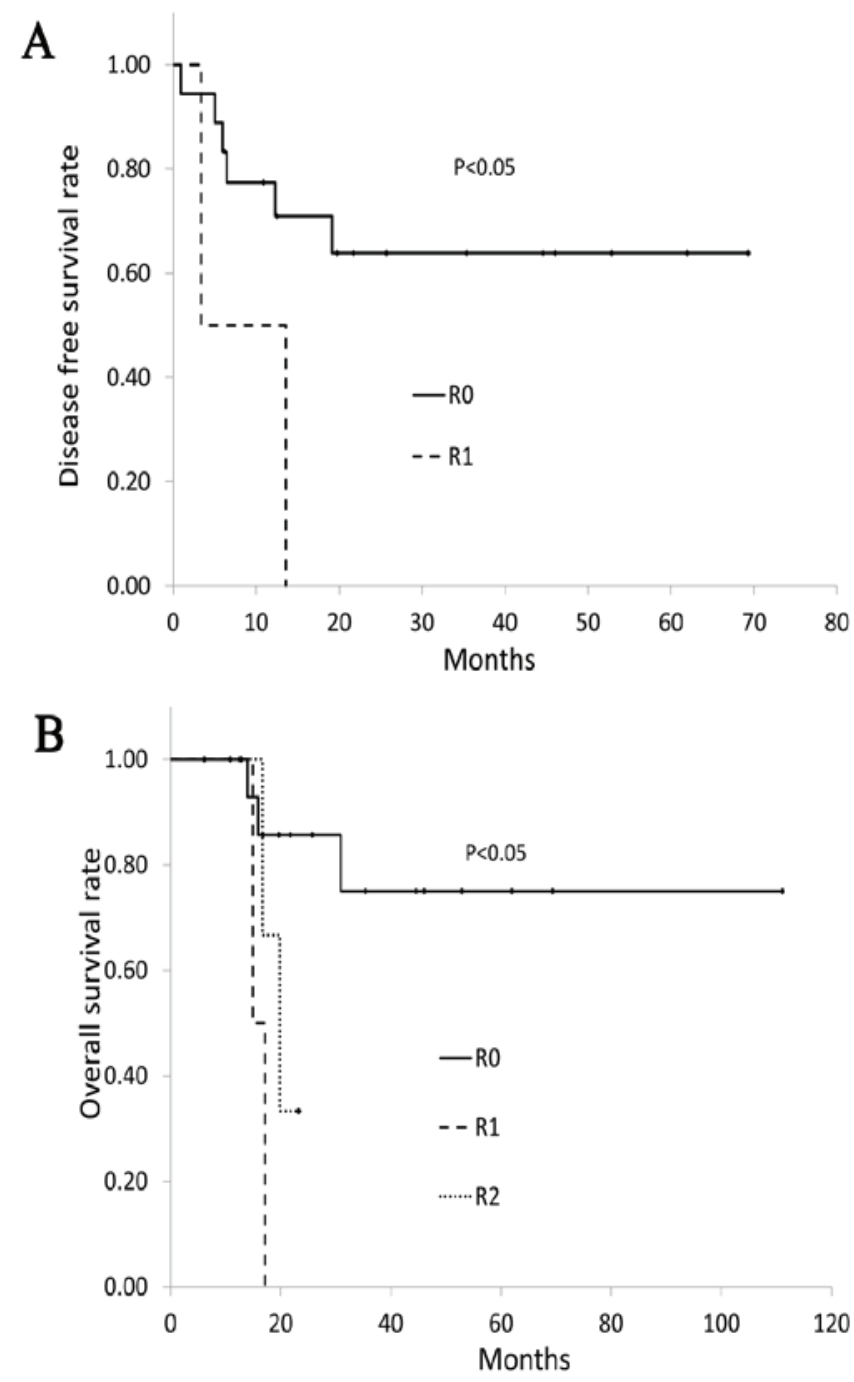

Figure 1. (A) Disease free survival according to R classification. Six of 13 patients with curative surgery had recurrence. Patients with curative surgery showed a significantly better disease-free survival than those with R1 resection $(\mathrm{P}<0.05)$. (B) Overall survival according to $\mathrm{R}$ classification. Patients with curative surgery showed a significantly better overall survival than the patients with $\mathrm{R} 1$ resection or those with $\mathrm{R} 2$ resection $(\mathrm{P}<0.01)$.

inadvertent dissection or rupture of the tumor, compared with $49 \%$ after en bloc resection (10). It is difficult to diagnose precisely whether or not an actual tumoral invasion exist during surgery, and therefore, en bloc multivisceral resection is needed to obtain clear resection margin (R0) according to these results.

Despite multivisceral resection for locally advanced colorectal cancer, the rate of $\mathrm{R} 0$ resections remains unsatisfactory, varying between 40 and 90\% (11). Eveno et.al. reported there were $89.5 \%$ R0 resections in patients with clinical T4 colorectal cancer, but also reported $\mathrm{R} 1$ resections were due to invasion of the resection margin of an adjacent organ in $5.2 \%$ patients and due to invasion of the circumferential resection margin in $9.9 \%$ patients and one $\mathrm{R} 2$ resection due to a large rectal cancer (5). Derici et al, in a retrospective study, reported there were $75.4 \% \mathrm{R} 0$ resections in rectal cancer patients with macroscopically direct invasion to adjacent organs or structures and $82.8 \% \mathrm{R} 0$ resection in patients who received neoadjuvant CRT (12). In our study, curative surgery 
was performed in 18 patients $(78.3 \%)$ after preoperative treatment. The rate of $\mathrm{R} 0$ resection in our study was slightly lower than that in previous reports, because we included patients of Stage 4 colorectal cancer in this study. Two patients with lung metastasis and one patients who had lung and liver metastases after CRT resulted in $\mathrm{R} 2$ resection due to the lung metastasis. And one patient had a R1 resection because histopathologic examination revealed malignant infiltration of the resected margin in the liver. $\mathrm{R} 0$ resection is known to be one of the most important prognostic factors in the management of locally advanced colorectal cancer (13). The oncologic outcomes of the multivisceral resections are reported as overall survival rates of $30-53 \%(2,5,12)$. In our study, we could not clearly demonstrate the benefit on the survival due to the small number of the investigated patients. But the R0 resection showed a better survival than $\mathrm{R} 1 / \mathrm{R} 2$ resection as shown in previous report (12). While five-year overall survival rate for patients who received curative resection was $75.0 \%$, and no patient with R1 and $\mathrm{R} 2$ resection survived 2 years. As for recurrence, six of 17 patients with curative surgery had recurrence. All recurrences occurred within two years of the surgical treatment, especially earlier in patients with $\mathrm{R} 1$ resection. So, careful follow-up to diagnose early recurrence, especially within two years, would be required.

As Nakafusa et al previously reported that only multivisceral resection was an independent factor for overall postoperative complications (14), extended en bloc multivisceral resection might involve serious complications, leading to an increase in morbidity and mortality. In previous reports, postoperative morbidity and mortality rates after mutivisceral resection tend to be higher ranging from 28.0 to $43.7 \%(2,8,12,15-17)$ and $\geq 13 \%(5,7,12,18)$, respectively. We observed a postoperative mortality of $4.3 \%$ and a morbidity of $39.1 \%$ in our study. Nakafusa et.al. reported that the rate of ileus in the multivisceral resection group was significantly higher than that in the single organ resection group in addition to infectious complications (14). In our study, as two cases of ileus and seven cases of infectious complications were observed as postoperative complication, we need to take into account the occurrence of ileus and infectious complications probably due to the large dead space after multivisceral resection.

Shukla et $a l$, in a retrospective study, reported on the feasibility of laparoscopic resection in the majority of T4 colon cancers with comparable short- and long-term clinical and oncologic outcomes, but also documented that surgeon bias and local extent of the tumor on preoperative imaging most likely played important roles in the selection of a laparoscopic or an open approach (17). In our study, a laparoscopic/ robotic multivisceral resection was achieved in seven patients without conversion to open surgery. And no intraoperative complications occurred during the study period. Operation time was slightly shorter in the laparoscopic/robotic surgery group than those in the open surgery group, but there was no statistical difference between the two groups. The amount of blood loss was significantly smaller in patients treated with laparoscopic/robotic surgery than those receiving open surgery. The number of harvested lymph node was similar between two groups. All patients without distant metastasis achieved R0 resection in the laparoscopic/robotic surgery group, except one who had lung metastasis at the time of diagnosis. So, laparoscopic/robotic surgery may also be considered as an alternative approach for $\mathrm{T} 4 \mathrm{~b}$ colorectal cancer after preoperative treatment, but the appropriate selection of patients with T4b colorectal cancer is necessary to perform laparoscopic surgery safely, and when needed, the conversion to open surgery must be considered. And further study is needed to confirm the long-term outcomes of laparoscopic/robotic surgery.

The present study had some limitations. First, this study was not a large-scale multicenter study, but the retrospective small study conducted at a single institute. Second, selection bias remains a concern. However, besides these limitations, current data still support en bloc multivisceral resections after preoperative treatment (CRT, CTx or RT) can be performed with acceptable postoperative morbidity and minimal mortality rates in patients with clinical T4 colorectal cancers and may offer a reasonable survival rate.

Multivisceral resection for locally advanced colorectal cancer invading into the adjacent organ after preoperative treatment (CRT, CTx or RT) can be performed with acceptable morbidity and minimal mortality. $\mathrm{R} 0$ resection improved overall and disease-free survival.

\section{Acknowledgements}

Not applicable.

\section{Funding}

No funding was received.

\section{Availability of data and materials}

All data generated or analyzed during this study are included in this published article.

\section{Authors' contributions}

T.N. was conceived the design of the manuscript and the analysis and interpretation of data and drafted the article. S.I. supervised the study. S.E., M.K., K.M., K.S., K.O., T.T., T.K., K.H., K.K. and H.N. participated in the design of this article and revised the paper critically for important intellectual content. T.W. supervised the study and gave final approval of the version to be published. All authors read and approved the final manuscript.

\section{Ethics approval}

The study was conducted with the approval of the Ethics Committee of the University of Tokyo [no. 3252-(5)].

\section{Consent for publication}

Not applicable.

\section{Competing interests}

The authors declare that they have no competing interests. 


\section{References}

1. Kashino I, Mizoue T, Tanaka K, Tsuji I, Tamakoshi A, Matsuo K, Wakai K, Nagata C, Inoue M, Tsugane S, et al; Research Group for Development and Evaluation of Cancer Prevention Strategies in Japan: Vegetable consumption and colorectal cancer risk: An evaluation based on a systematic review and meta-analysis among the Japanese population. Jpn J Clin Oncol 45: 973-979, 2015.

2. Sökmen S, Terzi C, Unek T, Alanyali H and Füzün M: Multivisceral resections for primary advanced rectal cancer. Int J Colorectal Dis 14: 282-285, 1999.

3. Sobin LH, Gospodarowicz MK and Wittekind Ch: UICC international union against cancer. TMN classification of malignant tumours. 7th edition. Wiley-lckwell, Chichester, UK, 2010.

4. Sugihara K: Response assessment of nonsurgical treatment for colorectal carcinoma. In: Japanese Society for Cancer of the Colon and Rectum, eds. Japanese Classification of Colorectal Carcinoma. 1st English ed. Tokyo, Japan: Kanehara \& Co Ltd; 77-82. 1997

5. Eveno C, Lefevre JH, Svrcek M, Bennis M, Chafai N, Tiret E and Parc Y: Oncologic results after multivisceral resection of clinical T4 tumors. Surgery 156: 669-675, 2014.

6. Gebhardt C, Meyer W, Ruckriegel S and Meier U: Multivisceral resection of advanced colorectal carcinoma. Langenbecks Arch Surg 384: 194-199, 1999.

7. Gezen C, Kement M, Altuntas YE, Okkabaz N, Seker M, Vural S, Gumus M and Oncel M: Results after multivisceral resections of locally advanced colorectal cancers: An analysis on clinical and pathological t4 tumors. World J Surg Oncol 10: 39, 2012.

8. Lehnert T, Methner M, Pollok A, Schaible A, Hinz U and Herfarth C: Multivisceral resection for locally advanced primary colon and rectal cancer: An analysis of prognostic factors in 201 patients. Ann Surg 235: 217-225, 2002.

9. Hunter JA, Ryan JA Jr and Schultz P: En bloc resection of colon cancer adherent to other organs. Am J Surg 154: 67-71, 1987.

10. Gall FP, Tonak J and Altendorf A: Multivisceral resections in colorectal cancer. Dis Colon Rectum 30: 337-341, 1987.
11. Hallet J, Zih FS, Lemke M, Milot L, Smith AJ and Wong CS: Neo-adjuvant chemoradiotherapy and multivisceral resection to optimize R0 resection of locally recurrent adherent colon cancer. Eur J Surg Oncol 40: 706-712, 2014.

12. Derici H, Unalp HR, Kamer E, Bozdag AD, Tansug T, Nazli O and Kara C: Multivisceral resections for locally advanced rectal cancer. Colorectal Dis 10: 453-459, 2008.

13. Smith JD, Nash GM, Weiser MR, Temple LK, Guillem JG and Paty PB: Multivisceral resections for rectal cancer. Br J Surg 99: 1137-1143, 2012.

14. Nakafusa Y, Tanaka T, Tanaka M, Kitajima Y, Sato S and Miyazaki K: Comparison of multivisceral resection and standard operation for locally advanced colorectal cancer: Analysis of prognostic factors for short-term and long-term outcome. Dis Colon Rectum 47: 2055-2063, 2004.

15. Nagasue Y, Akiyoshi T, Ueno M, Fukunaga Y, Nagayama S, Fujimoto Y, Konishi T, Nagasaki T, Nagata J, Mukai T, et al: Laparoscopic versus open multivisceral resection for primary colorectal cancer: Comparison of perioperative outcomes. J Gastrointest Surg 17: 1299-1305, 2013.

16. Kim KY, Hwang DW, Park YK and Lee HS: A single surgeon's experience with 54 consecutive cases of multivisceral resection for locally advanced primary colorectal cancer: Can the laparoscopic approach be performed safely? Surg Endosc 26: 493-500, 2012.

17. Shukla PJ, Trencheva K, Merchant C, Maggiori L, Michelassi F, Sonoda T, Lee SW and Milsom JW: Laparoscopic resection of t4 colon cancers: Is it feasible? Dis Colon Rectum 58: 25-31, 2015.

18. Eisenberg SB, Kraybill WG and Lopez MJ: Long-term results of surgical resection of locally advanced colorectal carcinoma. Surgery 108: 779-785, discussion 785-786, 1990. 